\title{
Litigations in orthopedics and trauma surgery: reasons, dynamics, and profiles
}

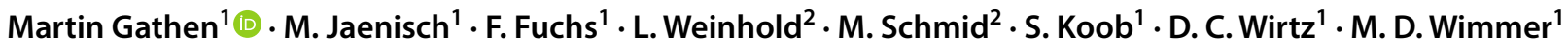

Received: 6 February 2021 / Accepted: 10 May 2021 / Published online: 27 May 2021

(c) The Author(s) 2021

\begin{abstract}
Background In recent literature, the increasing number of medical litigations, both in terms of the number of cases being filed and the substantive costs associated with lawsuits, has been described. This study aims to provide an overview of the profile of litigation for orthopedic and trauma surgery to describe the differences and the development of the number of cases over time.

Patients and Materials A retrospective review of all litigations between 2000 and 2017 was conducted using the institutional legal database. The causes of litigation were documented and classified into seven major categories. In addition to plaintiff characteristics, the litigation outcomes and the differences between emergency and elective surgery were analyzed.

Results A total of 230 cases were evaluated. The mean age of the plaintiffs was $44.6 \pm 20.1$ years, and $56.8 \%$ were female. The main reasons for litigation were claimed inappropriate management (46.1\%), misdiagnosis (22.6), and poor nursing care (8.3\%). Significantly more litigations were filed against surgeons of the orthopedic subspecialty compared with trauma surgeons $(78 \% ; p \leq 0.0001)$. There were significantly fewer litigations per 1000 cases filed overall in 2009-2017 (65\% less; $p=0.003$ ) than in 2000-2008.

Conclusion Our results could not confirm the often-stated trend of having more litigations against orthopedic and trauma surgeons. Although the absolute numbers increased, the number of litigations per 1000 patients treated declined. Patients who underwent elective surgery were more likely to file complaints than emergency patients.
\end{abstract}

Keywords Litigation · Lawsuit · Orthopedic surgery $\cdot$ Treatment errors $\cdot$ Medical malpractice

\section{Introduction}

The field of orthopedic surgery has a high incidence of medical malpractice claims, resulting in a relative risk of 99\% for each surgeon to receive at least one claim in his/her career [1]. Many publications have described an increase in the number of lawsuits against medical professionals across all fields of practice [2-5]. The increasing demands on the patient side potentially influenced by incorrect information communicated through the internet or social media

Martin Gathen

Martin.gathen@ukbonn.de

1 Department of Orthopaedics and Trauma Surgery, University Hospital of Bonn, Venusberg-Campus 1, 53127 Bonn, Germany

2 Institute of Medical Biometry, Informatics and Epidemiology, University Hospital of Bonn, Bonn, Germany platforms, the escalating willingness to regress and litigate, and the misconception about the limits of the medically possible outcomes are considered potential reasons [6-9]. Patient satisfaction and patient or customer service have been neglected for a long time by the medical community compared with commercial branches [10]. Studies have demonstrated that physicians who received low patient satisfaction ratings were more likely to have malpractice lawsuits than those with high ratings [8]. Training programs for patient-centered communication and empathy and intervention programs for improving patient satisfaction are recent prevention strategies [11-14].

Nevertheless, litigations require extensive resources and produce considerable expenses for society and healthcare systems. In 2000-2006, more than US\$ 321 million were paid in orthopedic surgery-related settlements in the United Kingdom [15]. The cost of defending US malpractice claims, including legal costs, awards, and underwriting costs, was estimated at US\$ 6.5 billion in 2001 [16, 17]. 
Only a few studies have examined the subject of litigation in orthopedic and trauma surgery and investigated the main reasons, profiles, and trends. Therefore, this study aims to give an overview of the current status of litigation procedures in orthopedic and trauma surgery by evaluating the cases of a level I trauma center in Germany. The authors further seek to evaluate the claimed increase in litigation procedures in the field of orthopedic and trauma surgery. In addition, the differences between cases of elective and emergency surgery and the changes in the dynamics of the profile of litigation procedures over time are presented.

\section{Patients and methods}

A retrospective single-center cohort study was performed by analyzing all litigations filed between January 2000 and December 2017. The institution is a 120-bed university hospital serving as a tertiary care center for spine surgery and arthroplasty. The institution is also a level I trauma center. The study was approved by the local institutional review board (No. 080/19).

Data were obtained from the legal department's database. The inclusion criterion was that the cases required legal assistance in the time period described. Cases involving minor complaints that were not dealt with by the legal department were excluded. The cases were anonymized and examined by two investigators. Epidemiological data and plaintiff characteristics, including age, sex, and medical history, were collected (Table 1). The causes for litigation were documented and classified into seven major categories (A-G). Additional subgroups have been identified for a more detailed examination (Tables 2, 3). The stated symptoms and complaints resulting from the potential malpractice were classified into eight major categories (A-H) and further subgroups (Table 4).

The litigation outcomes and differences between emergency and elective surgery were also analyzed. The entire investigation period was divided into two equivalent periods of time (2000-2008 and 2009-2017). These time periods were compared in terms of the rate of complaints. Further, the relative number of litigations in relation to the absolute number of patients treated was analyzed.

\section{Statistical analysis}

The data characteristics were described as the means with standard deviations (SD) for the continuous variables and frequency distributions with percentages for the categorical variables. The response variables were defined as the number of litigations related to the treatment years 2000-2017 and the number of litigations resulting in a favorable outcome for the plaintiff. The differences between trauma surgery and orthopedics and between the periods 2000-2008
Table 1 Descriptive statistics and overview of the most important variables

\begin{tabular}{lll}
\hline Characteristics & & \\
\hline$N$ & 230 & \\
Period ( $\leq 2008), n(\%)$ & 88 & $38.3 \%$ \\
Period $(>2008), n(\%)$ & 142 & $61.7 \%$ \\
Orthopedic, $n(\%)$ & 157 & $68.3 \%$ \\
Trauma surgery, $n(\%)$ & 73 & $31.7 \%$ \\
Age (time of treatment), mean (SD) & 47.6 & 20.1 \\
Sex male (\%) & 99 & $43.2 \%$ \\
Time (years) between treatment and litigation, median (range) & 1 & $0-9$ \\
Liability, $n(\%)$ & 55 & $23.9 \%$ \\
Liability exist & 121 & $52.6 \%$ \\
No liability & 1 & $0.4 \%$ \\
Missing data & 53 & $23 \%$ \\
Causes of litigation, main categories, $n$ (\%) & & \\
A2: inappropriate management/mistreatment/failure to apply fixation & 106 & $46.1 \%$ \\
A1: misdiagnosis/delay/failure to diagnose (frx-dislocation-rupture) & 52 & $22.6 \%$ \\
G2: poor nursing care, inappropriate moving by staff, injuries in hospital, etc & 19 & $8.3 \%$ \\
B1: iatrogenic nerve damage & 18 & $7.8 \%$ \\
Symptoms and complaints. main categories, $n$ (\%) & 290 & \\
H4: mobility problems & 108 & $37.2 \%$ \\
H1: discomfort and pain & 46 & $15.9 \%$ \\
E3: poor surgery outcome requiring reoperation & 44 & $15.2 \%$ \\
B1: Iatrogenic nerve damage & 27 & $9.3 \%$ \\
\hline
\end{tabular}


Table 2 List of all categories concerning the grounds for litigation sorted by orthopedic and trauma surgery

\begin{tabular}{|c|c|c|c|c|}
\hline \multirow[t]{2}{*}{ Categories for causes of litigation } & \multicolumn{2}{|c|}{ Absolute } & \multicolumn{2}{|c|}{ Percentage } \\
\hline & Orth & Trauma & Orth & Trauma \\
\hline A1: misdiagnosis/delay/failure to diagnose (frx-dislocation-rupture) & 31 & 21 & 19.7 & 28.8 \\
\hline A2: inappropriate management/mistreatment/failure to apply fixation & 73 & 33 & 46.5 & 45.2 \\
\hline B1: iatrogenic nerve damage & 12 & 6 & 7.6 & 8.2 \\
\hline B2: latrogenic damages (fracture, tendon, or artery rupture) & 5 & 2 & 3.2 & 2.7 \\
\hline $\mathrm{C} 1$ : infections & 4 & 1 & 2.5 & 1.4 \\
\hline D4: allergies & 1 & 0 & 0.6 & 0 \\
\hline E1: inappropriate metal work placement & 5 & 0 & 3.2 & 0 \\
\hline E2: incorrect/inappropriate/poor surgery (no reference for second intervention) & 4 & 3 & 2.5 & 4.1 \\
\hline E3: poor surgery outcome requiring reoperation & 2 & 2 & 1.3 & 2.7 \\
\hline F1: non-union & 1 & 0 & 0.6 & 0 \\
\hline G1: inadequate follow-up & 2 & 1 & 1.3 & 1.4 \\
\hline G2: poor nursing care, inappropriate moving by staff, injuries in hospital, etc & 15 & 4 & 9.6 & 5.5 \\
\hline G3: no consent & 2 & 0 & 1.3 & 0 \\
\hline
\end{tabular}

Table 3 List of all categories concerning symptoms and complaints after treatment sorted by orthopedic and trauma surgery

\begin{tabular}{|c|c|c|c|c|}
\hline \multirow[t]{2}{*}{ Categories for stated symptoms and complaints } & \multicolumn{2}{|c|}{ Absolute } & \multicolumn{2}{|c|}{ Percentage } \\
\hline & Orth & Trauma & Orth & Trauma \\
\hline A1: misdiagnosis/delay/failure to diagnose (frx-dislocation-rupture) & 1 & 0 & 0.5 & 0 \\
\hline A2: inappropriate management/mistreatment/failure to apply fixation & 2 & 0 & 1 & 0 \\
\hline B1: iatrogenic nerve damage & 21 & 6 & 10.3 & 7 \\
\hline B2: iatrogenic damages (fracture, tendon, or artery rupture) & 5 & 7 & 2.5 & 8.1 \\
\hline C1: infections & 14 & 2 & 6.9 & 2.3 \\
\hline C3: skin problems/pressure sores & 13 & 3 & 6.4 & 3.5 \\
\hline D3: bleeding & 1 & 0 & 0.5 & 0 \\
\hline D4: allergies & 2 & 1 & 1 & 1.2 \\
\hline D6: death & 5 & 2 & 2.5 & 2.3 \\
\hline E3: poor surgery outcome requiring reoperation & 33 & 11 & 16.2 & 12.8 \\
\hline G1: inadequate follow-up & 1 & 1 & 0.5 & 1.2 \\
\hline G2: poor nursing care, inappropriate moving by staff, injuries in hospital, etc & 2 & 1 & 1 & 1.2 \\
\hline H1: discomfort and pain & 31 & 15 & 15.2 & 17.4 \\
\hline H2: amputation & 0 & 1 & 0 & 1.2 \\
\hline H3: deformity & 0 & 1 & 0 & 1.2 \\
\hline H4: mobility problems & 73 & 35 & 35.8 & 40.7 \\
\hline
\end{tabular}

Table 4 Target variable number of litigations per 1000 cases

\begin{tabular}{llllr}
\hline Characteristic & RR & CI (lower) & CI (upper) & $\operatorname{Pr}(>|z|)$ \\
\hline Intercept & 1.09 & 0.79 & 1.46 & 0.5969 \\
$\begin{array}{l}\text { Second time period } \\
\quad 0.44\end{array}$ & 0.32 & 0.61 & $<0.0001$ \\
$\begin{array}{l}\text { Ortho09-2017) } \\
\text { Orthopedic }\end{array}$ & 1.74 & 1.26 & 2.42 & 0.0001 \\
\hline
\end{tabular}

and 2009-2017 regarding litigations that resulted in existing liability for the accused were assessed descriptively.
Further, we examined the effects of the explanatory variables subspecialties (trauma surgery vs. orthopedics) and time period (2000-2009 vs. 2010-2017) on the number of litigations using a negative binomial regression model. Each year was considered one unit of observation. For easy interpretation, we included the variable number of treatments (in 1000) as an offset in the regression model. Consequently, the effect estimates could be interpreted at the level of number of litigations per 1000 treatments. The estimates obtained from the model were presented as rate ratios (RR) with a $95 \%$ confidence interval $(\mathrm{CI})$ for the negative binomial regression model. $p$ values $<0.05$ were considered significant. All 
analyses were carried out using the R Software for Statistical Computing version 4.0.3.

\section{Results}

For over a period of 18 years (2000-2017), $n=267,882$ cases were treated and resulted in $n=230$ cases of litigation $(0.086 \%)$. The mean age of the plaintiffs was $47.6 \pm 20.1$ (range 0-99) years. In total, $43.2 \%$ of the patients $(n=99)$ were male, and $56.8 \%(n=131)$ were female. The number of patients treated increased steadily over the course of the observed period (Fig. 1). In 2000, there were 3810 patients treated in the outpatient area and 1752 inpatient patients. There were 5111 outpatients and 2,365 inpatient cases in 2008 and 20,287 outpatients and 4209 inpatient cases in 2017. The total number of cases in 2017 was 4.5 times higher than that in 2000 (Fig. 2).

\section{Reasons for litigation}

The main reasons for litigation were inappropriate clinical management in organization processes $(46.1 \%)$, claimed misdiagnosis (22.6\%), and subjective experienced poor nursing care (8.3\%) (Table 2).

\section{Symptoms complained}

The most common symptoms and complaints raised in the context of the litigation were mobility problems (37.2\%), discomfort and pain (15.9\%), and poor surgery outcome requiring reoperation $(15.2 \%)$ (Table 3$)$.

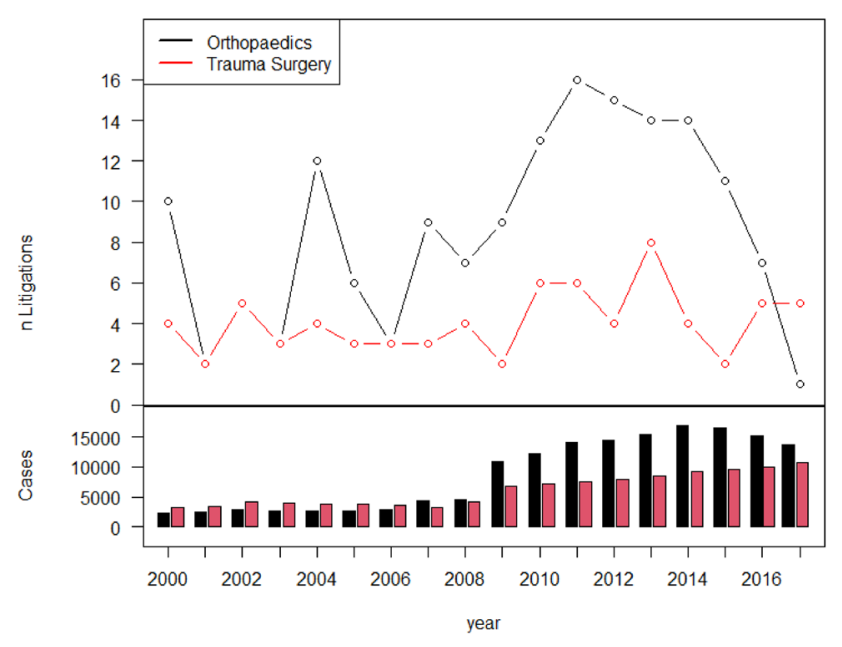

Fig. 1 Upper half: absolute number of cases filed per year. Lower half: absolute number of patients treated (inpatient=red/outpatient $=$ black)

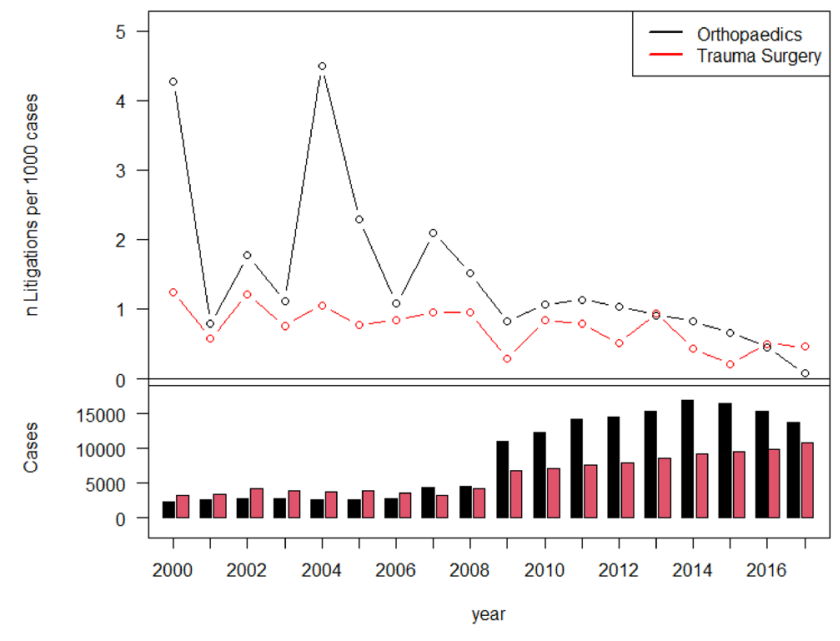

Fig. 2 Upper half: rate of lawsuits per 1000 cases per year. Lower half: absolute number of patients treated (inpatient $=$ red/outpatient $=$ black)

\section{Trends}

The absolute number of litigations was $n=88$ in the first time period (2000-2008) and $n=142$ in the second time period (2009-2017). Compared with the first time period, there were significantly fewer litigations per 1000 cases in the second time period (56\% less litigations; RR 0.44, CI $0.32-0.61, p<0.0001)$.

\section{Elective surgery vs. trauma surgery}

The average rate of litigations per 1000 cases was 1.09 in the first time period and 0.48 in the second time period for trauma surgeons. The average rate was 1.90 per 1000 cases for orthopedic surgeons in 2000-2008 and 0.83 after 2008. Significantly more litigations were filed against surgeons of the orthopedic subspecialties than against trauma surgeons (74\% more litigations; RR 1.74, CI 1.26-2.42, $p=0.0001$ ) (Table 4).

\section{Discussion}

Our results could not confirm the often claimed increase in litigation procedures in the field of orthopedic and trauma surgery. Patients who underwent elective surgery were significantly more likely to file complaints than emergency patients. Well-designed studies about litigations in orthopedic and trauma surgery are rare. The present study aims to provide an overview of litigations using the example of a level I trauma center in Germany. Almost every surgeon will encounter lawsuits during his/her career. Jena et al. evaluated the risk of facing malpractice claims according to 
physician specialty. Surgical specialties always showed the highest probability of litigation. The risk of being sued as an orthopedic surgeon per year was almost twice as high (14\%) as the average across all disciplines (7.4\%) [17].

The most noticeable result of our study is the significant percentage decrease in litigations filed in our institution between 2000 and 2017. The absolute number of cases filed increased, potentially resulting in a subjective perception of a stark increase in litigation. However, the average rate of lawsuits per 1000 cases per year decreased from 1.54 in 2000-2008 to 0.67 in 2009-2017 because of an absolute increase in cases treated.

Many authors have described different results and increasing legal actions against surgeons. Reasons, such as poor quality of patient-physician relationship or the trend of considering medicine as a service that requires financial compensation, have been reported [2-5, 18]. Agout et al. found a significant increase in legal actions, from 9 cases in 2006 to 28 cases in 2015 ( $p=0.04)$. Nevertheless, the authors presented absolute numbers of litigations per year only, and a possible change in the absolute number of treated cases was not reported. Erivan et al. reported an increase in patient complaints after arthroplasty between 2006 and 2016 from $0.2 \%$ up to $1.2 \%$ [5]. Cichost et al. analyzed a national legal database and found an increasing frequency of litigation (215\%) and pay-outs (280\%) during the period of 1988-2013 [18].

What are the potential reasons for the decrease in litigations in our collective? In 2012, our institution established a hospital customer service for both praise and complaint management. Studies have indicated that the introduction of a professional service for complaints is potentially important in patient satisfaction and quality of care [19, 20]. Eastaugh et al. stated that failed communication with patients and their families is the most common cause of malpractice suits [21].

Furthermore, many expert medical testimonies are performed in our institution, which is a university teaching hospital, thus giving it broad expertise in medical litigations. As all residents and senior surgeons are involved in the expert medical testimony procedures, the mental presence of potential malpractice procedures can lead to a higher level of alertness to avoid a lawsuit.

Finally, an international trend has emerged where the number of hospitals is being reduced in favor of fewer highly specialized centers. For most inpatient treatments, a higher volume was found to be associated with better patient safety and outcomes [22-25]. Erivan et al. showed an increase in the number of trauma surgeries and arthroplasties (43.6\%) over a 10 -year period, with no significant increase in complications [5]. The German Medical Association publishes the annual total figures of cases processed by the official arbitration board. The data showed stable values, with 10,705 claims in 2019, 12,053 claims in 2014, and 11,016 claims in
2010 [26]. Assuming an aging population with an increase in patient treatments per hospital, these data confirmed our results.

Another notable result is the significant difference in the number of litigations in trauma surgery compared with elective orthopedic surgery. After 2008, the estimated average rate of litigation was 0.48 per 1000 cases per year in trauma and emergency surgery and 0.83 in elective orthopedic surgery, such as spine surgery and total joint replacements $(p=0.0001)$. Tarantino et al. retrospectively analyzed 243 claims after orthopedic surgery and found a similar trend: elective surgery was responsible for $61 \%$ of litigations whereas only $39 \%$ of the claims were filed due to trauma surgery. Procedures most frequently involved in claims were total hip arthroplasty and lumbar decompression [27]. A study comparing a trauma department and 12 surgical specialties in a single center found the fewest events and lawsuits per 10,000 patients days for trauma patients. The authors conclude that despite the perception, trauma care has better claim experience than most surgical specialties [28]. A possible reason for the difference may be higher patient expectations prior to an elective surgery compared to an unforeseen operation due to an injury. Discrepancies between the patient and the surgeon regarding the expected result of a surgical procedure have often been described with consistently higher expectations on the patients' side [29, 30].

The incidence of medical errors is difficult to determine because its definition differs depending on the study. Moreover, the frequency and type of errors vary greatly between the field of practice and the methods of detection in different publications [31]. The reported rate for complications in trauma surgery is $21.1 \%$, with an error incidence of $8.7 \%$ [7]. Medically and legally, the line between a medical error and a hardly preventable complication can be very thin. Furthermore, the intention for legal action may depend on how serious the consequences of a medical error turned out to be, and therefore, not every case of medical malpractice will end in litigation or a malpractice claim. Stewart et al. evaluated the risk of malpractice lawsuits and compared elective, urgent, and trauma surgery. In contrast to our results, the authors found no significant difference between the groups and reported a low risk of litigation [32].

Finally, this study investigated the common reasons that trigger litigation. The main causes of litigation claims in elective and trauma surgery were inappropriate management/ mistreatment at $46.5 \%$ for orthopedic patients and $45.2 \%$ for trauma patients and misdiagnosis/delay/failure to diagnose at $19.7 \%$ for orthopedic patients and $28.8 \%$ for trauma patients. Regarding the symptoms and complaints reported, mobility problems were the most common at $37.2 \%$, followed by discomfort and pain at $15.9 \%$. Other authors reported different values and reasons, such as surgical-site infection as the 
main reason at 50.7\% [3] and failure in protecting structures in the surgical field $[33,34]$.

This study presents data from a German university hospital of orthopedic and trauma surgery and the litigations it faced over a period of 18 years. This work has several limitations. First, as each country has different laws for handling medical litigations, the results can only be generalized to a limited extent. Second, this is a retrospective single-center study, and no control group was included. For simplification, the reasons for litigation have been classified into categories. Thus, true reasons and motivations behind individual litigations can hardly be determined.

In conclusion, the findings could not confirm the oftenstated trend of an increasing number of litigations against orthopedic and trauma surgeons. Claimed inappropriate management was the main reason for litigation in our institution. The risk of facing litigation was significantly higher for surgeons performing elective orthopedic surgery than for trauma surgeons.

Funding Open Access funding enabled and organized by Projekt DEAL. This research received no specific grant from any funding agency in public, commercial, or not-for-profit sectors.

\section{Declarations}

Conflict of interest All authors declare that they have no conflict of interest.

Informed consent All information was anonymized and the publication includes no images that may identify a person. Informed consent is obtained for every surgery in our institution.

Ethical approval This study was approved by the local institutional review board (Ethics Committee No. 080/19).

Open Access This article is licensed under a Creative Commons Attribution 4.0 International License, which permits use, sharing, adaptation, distribution and reproduction in any medium or format, as long as you give appropriate credit to the original author(s) and the source, provide a link to the Creative Commons licence, and indicate if changes were made. The images or other third party material in this article are included in the article's Creative Commons licence, unless indicated otherwise in a credit line to the material. If material is not included in the article's Creative Commons licence and your intended use is not permitted by statutory regulation or exceeds the permitted use, you will need to obtain permission directly from the copyright holder. To view a copy of this licence, visit http://creativecommons.org/licenses/by/4.0/.

\section{References}

1. Ciofu DC (2011) The frequency and severity of medical malpractice claims: high risk and low risk specialties. Maedica 6(3):230-231
2. Mouton J, Gauthé R, Ould-Slimane M, Bertiaux S, Putman S, Dujardin F (2018) Litigation in orthopedic surgery: what can we do to prevent it? Systematic analysis of 126 legal actions involving four university hospitals in France. Orthop Traumatol Surg Res 104(1):5-9. https://doi.org/10.1016/j.otsr.2017.11.002

3. Agout C, Rosset P, Druon J, Brilhault J, Favard L (2018) Epidemiology of malpractice claims in the orthopedic and trauma surgery department of a French teaching hospital: a 10-year retrospective study. Orthop Traumatol Surg Res 104(1):11-15. https://doi.org/ 10.1016/j.otsr.2017.11.007

4. Pappas ND, Moat D, Lee DH (2014) Medical malpractice in hand surgery. J Hand Surg 39(1):168-170. https://doi.org/10.1016/j. jhsa.2013.06.021

5. Erivan R, Chaput T, Villatte G, Ollivier M, Descamps S, Boisgard S (2018) Ten-year epidemiological study in an orthopaedic and trauma surgery centre: are there risks involved in increasing scheduled arthroplasty volume without increasing resources? Orthop Traumatol Surg Res 104(8):1283-1289. https://doi.org/ 10.1016/j.otsr.2018.08.009

6. Ahmed SA et al (2019) Malpractice litigation following traumatic fracture. J Bone Joint Surg 101(7):e27. https://doi.org/10.2106/ JBJS.18.00853

7. Bosma E, Veen EJ, Roukema JA (2011) Incidence, nature and impact of error in surgery. Br J Surg 98(11):1654-1659. https:// doi.org/10.1002/bjs.7594

8. Stelfox HT, Gandhi TK, Orav EJ, Gustafson ML (2005) The relation of patient satisfaction with complaints against physicians and malpractice lawsuits. Am J Med 118(10):1126-1133. https://doi. org/10.1016/j.amjmed.2005.01.060

9. Floyd TK (2008) Medical malpractice: trends in litigation. Gastroenterology 134(7):1822-1825. https://doi.org/10.1053/j.gastro. 2008.05.001

10. Shan L et al (2016) Patient satisfaction with hospital inpatient care: effects of trust, medical insurance and perceived quality of care. PLoS ONE 11(10):e0164366. https://doi.org/10.1371/journ al.pone. 0164366

11. Noordman J, Post B, A. a. M. van Dartel, J. M. A. Slits, and T. C. Olde Hartman, (2019) Training residents in patient-centred communication and empathy: evaluation from patients, observers and residents. BMC Med Educ 19(1):128. https://doi.org/10.1186/ s12909-019-1555-5

12. van den Brink-Muinen A et al (2000) Doctor-patient communication in different European health care systems. Patient Educ Couns 39(1):115-127. https://doi.org/10.1016/S0738-3991(99)00098-1

13. Otani K, Herrmann PA, Kurz RS (2011) Improving patient satisfaction in hospital care settings. Health Serv Manage Res 24(4):163-169. https://doi.org/10.1258/hsmr.2011.011008

14. TavakolySany SB, Behzhad F, Ferns G, Peyman N (2020) Communication skills training for physicians improves health literacy and medical outcomes among patients with hypertension: a randomized controlled trial. BMC Health Serv Res 20(1):60. https:// doi.org/10.1186/s12913-020-4901-8

15. Atrey A, Gupte CM, Corbett SA (2010) Review of successful litigation against english health trusts in the treatment of adults with orthopaedic pathology: clinical governance lessons learned. J Bone Joint Surg Am 92(18):e36. https://doi.org/10.2106/JBJS.J. 00277

16. Anderson GF, Hussey PS, Frogner BK, Waters HR (2005) Health spending in the United States and the rest of the industrialized world. Health Aff (Millwood) 24(4):903-914. https://doi.org/10. 1377/hlthaff.24.4.903

17. Jena AB, Seabury S, Lakdawalla D, Chandra A (2011) Malpractice risk according to physician specialty. N Engl J Med 365(7):629-636. https://doi.org/10.1056/NEJMsa1012370 
18. Cichos KH et al (2019) Trends and risk factors in orthopedic lawsuits: analysis of a national legal database. Orthopedics 42(2):e260-e267. https://doi.org/10.3928/01477447-20190211-01

19. Mattarozzi K, Sfrisi F, Caniglia F, De Palma A, Martoni M (2017) What patients' complaints and praise tell the health practitioner: implications for health care quality. A qualitative research study. Int J Qual Health Care 29(1):83-89. https://doi.org/10.1093/ intqhe/mzw 139

20. Råberus A, Holmström IK, Galvin K, Sundler AJ (2019) The nature of patient complaints: a resource for healthcare improvements. Int J Qual Health Care 31(7):556-562. https://doi.org/10. 1093/intqhe/mzy215

21. Eastaugh SR (2004) Reducing litigation costs through better patient communication. Physician Exec 30(3):36-38

22. Nimptsch U, Mansky T (2017) Hospital volume and mortality for 25 types of inpatient treatment in German hospitals: observational study using complete national data from 2009 to 2014. BMJ Open 7(9):e016184. https://doi.org/10.1136/bmjopen-2017-016184

23. Adkins ZB, Malik AT, Jain N, Yu E, Kim J, Khan SN (2019) Does hospital volume affect outcomes in spine surgeries? A systematic review. Clin Spine Surg 32(7):285-294. https://doi.org/10.1097/ BSD.0000000000000785

24. Veronese N, Maggi S (2018) Epidemiology and social costs of hip fracture. Injury 49(8):1458-1460. https://doi.org/10.1016/j.injury. 2018.04.015

25. Cummings SR, Melton LJ (2002) Epidemiology and outcomes of osteoporotic fractures. Lancet 359(9319):1761-1767. https://doi. org/10.1016/S0140-6736(02)08657-9

26. "Behandlungsfehler-Statistik." https://www.bundesaerztekammer. de/patienten/gutachterkommissionen-schlichtungsstellen/behan dlungsfehler-statistik/. Accessed 06 Jan 2021

27. Tarantino U, Via AG, Macrì E, Eramo A, Marino V, Marsella LT (2013) Professional liability in orthopaedics and traumatology in
Italy. Clin Orthop Relat Res 471(10):3349-3357. https://doi.org/ 10.1007/s11999-013-3165-6

28. McGwin G, Wilson SL, Bailes J, Pritchett P, Rue LW (2008) Malpractice risk: trauma care versus other surgical and medical specialties. J Trauma 64(3):607-612. https://doi.org/10.1097/TA. 0b013e 3181653411 (discussion 612-613)

29. Jourdan C et al (2012) Comparison of patient and surgeon expectations of total hip arthroplasty. PLoS ONE 7(1):e30195. https:// doi.org/10.1371/journal.pone.0030195

30. Lattig F et al (2013) A comparison of patient and surgeon preoperative expectations of spinal surgery. Spine 38(12):1040-1048. https://doi.org/10.1097/BRS.0b013e318269c100

31. Triacca M-L, Gachoud D, Monti M (2018) Kognitive Aspekte medizinischer Fehler. Swiss Med Forum. https://doi.org/10.4414/ smf.2018.03060

32. Stewart RM et al (2005) Trauma surgery malpractice risk: perception versus reality. Ann Surg 241(6):969-975. https://doi.org/10. 1097/01.sla.0000164179.48276.45 (discussion 975-977)

33. Matsen FA, Stephens L, Jette JL, Warme WJ, Posner KL (2013) Lessons regarding the safety of orthopaedic patient care: an analysis of four hundred and sixty-four closed malpractice claims. J Bone Joint Surg Am 95(4):e201-208. https://doi.org/10.2106/ JBJS.K.01272

34. Swarup I, Henn CM, Gulotta LV, Henn RF (2019) Patient expectations and satisfaction in orthopaedic surgery: a review of the literature. J Clin Orthop Trauma 10(4):755-760. https://doi.org/ 10.1016/j.jcot.2018.08.008

Publisher's Note Springer Nature remains neutral with regard to jurisdictional claims in published maps and institutional affiliations. 